\title{
The Scope of Cardiac Surgery at a National Cardiothoracic Center of Excellence (NCTCE) in Nigeria: A 3-Year Review
}

\author{
Nwafor IA*, Eze JC, Anyanwu CH, Ezemba N, Onyia UOC, Enwerem NU, Nwafor MN, Chinawa JM and Anisuba B \\ Department of Surgery, NCTCE, Enugu, Nigeria
}

\begin{abstract}
Background: The heart with its intrinsic and indispensable function is a vital organ in the human body. Surgical management of diseases affecting it was initially thought to be incompatible with life. Surgeons who desired the respect of their colleagues were barred from operating on the heart, on the ground that human knowledge is very limited in that area. This notion was however changed in 1893 when laceration in the left ventricle was successfully repaired at Chicago Provident Hospital in USA. Three years later, the same feat was successfully reproduced several times in Frankfurt Germany. Also by 1938 in Boston Children Hospital, Massachusetts, USA, Robert Gross successfully interrupted a PDA in a 7-yearold child. This was followed by successful repair of coarctation of the aorta and the famous blue baby operation, all in 1944, thus unequivocally, proving that successful operation on the heart was tenable in the western world. On the contrary, in the early 1940s and 1950s, cardiac diseases requiring surgery for whole or part of their management were thought to be rare in Nigeria in particular and Africa in general. The establishment of cardiac registry at $\mathrm{UCH}$, Ibadan in western Nigeria, in 1964 revealed all types of cardiac diseases including those requiring surgical intervention. Today, many cardiac diseases are treated by surgery in NCTCE, UNTH, Enugu and other centers in Nigeria. The western world is abandoning the perfected conventional open access cardiac surgery for minimal invasive cardiac surgery with comparable results vis-à-vis efficacy.
\end{abstract}

Aim/Objective: To determine the scope of cardiac surgery at the National Cardiothoracic Center of Excellence and compare same with the continental and international standard.

Materials and method: This is a retrospective study. From March, 2013 to February, 2016, (3 years) all case records of those that underwent cardiac operations at NCTCE were retrieved and analyzed using simple arithmetic method. Those who were diagnosed but could not be operated on, who either died or referred abroad due to the complexity of their cardiac diseases were excluded from the study.

Results: During this period, spanning 3 years, a total of 209 cardiac operations were carried out, about 69.7 cases per year. The age range of the patients that were operated was 1 year to 72 years with a mean of 2.9. Of this number, $128(61.2 \%)$ were males and $81(38.8 \%)$ were females with a ratio of 1.6: 1 . Also, open heart procedures constituted about $125(59.6 \%)$, while closed heart procedures were $84(40.4 \%)$. Out of 125 cases of open heart procedures, $79(63.1 \%)$ were for acquired adult heart diseases while $46(36.9 \%)$ were for congenital heart diseases. Mean hospitalization at the intensive care unit was 72 hours while the mean hospital stay was ten days. Mortality was about 25 (12.0\%).

Conclusion: From the results, NCTCE carried out significant number of cases during the period when compared to previous years. However, the youngest age group was 1 year old, suggesting that those below that age group were referred out. The mean hospital stay is relatively longer, suggesting that complications might have contributed.

Keywords: NCTCE; Congenital; Heart; Cardiac surgery; Intensive care unit

Abbreviations: UCH: University College Hospital; MAPCAS: Major Aortopulmonary Collaterals; UNTH: University of Nigeria Teaching Hospital; ICU: Intensive Care Unit; NCTCE: National Cardiothoracic Center of Excellence; CHD: Congenital Heart Defect

\section{Introduction}

University of Nigeria Teaching Hospital, Enugu was designated National Cardiothoracic Center Of Excellence (NCTCE) in 1984 by the Federal Government of Nigeria [1] for being the first hospital to perform open heart operation in Nigeria precisely in February $1^{\text {st }} 1974$, among other feats. From 1974 to 1981, it performed about 46 cases of cardiac surgeries in children with age range (6 months-16 years). Out of this 46, 25 were for congenital heart defects while 21 were for acquired heart disease [2]. Comparatively, UCH, Ibadan performed 5 cases of open heart surgery between 1978 and 1983 [3]. By the year 2000, a total of 102 cases of open heart and 48 cases of closed heart surgeries were carried out in NCTCE, UNTH, Enugu, Nigeria [4].
The surgery of the heart is divided into extra-cardiac and intracardiac or open heart and closed heart surgery. Usually the indications are pericardial diseases, congenital heart diseases (simple to complex), valvular heart diseases, cardiomyopathy and coronary heart diseases as well as cardiac injuries. Others are arrhythmia surgery (pacemaker implantations or Maze procedures), cardiac tumours, cardiac assist devices and heart transplantations, ascending and descending aortic aneurysms.

*Corresponding author: Dr. IA Nwafor, Department of Surgery, NCTCE, Enugu, Nigeria, Tel: +2348037784860; E-mail: i gbochinanya2@yahoo.com

Received March 25, 2017; Accepted April 20, 2017; Published April 24, 2017

Citation: Nwafor IA, Eze JC, Anyanwu CH, Ezemba N, Onyia UOC, et al. (2017) The Scope of Cardiac Surgery at a National Cardiothoracic Center of Excellence (NCTCE) in Nigeria: A 3-Year Review. J Vasc Med Surg 5: 308. doi: 10.4172/23296925.1000308

Copyright: $\odot 2017$ Nwafor IA, et al. This is an open-access article distributed under the terms of the Creative Commons Attribution License, which permits unrestricted use, distribution, and reproduction in any medium, provided the original author and source are credited. 
Few other medical disciplines have required for their development the degree of daring courage, tenacity, and drive that characterized the efforts of early pioneers in the field of congenital cardiac surgery. Only a century ago, Theodore Billroth publicly condemned the dream of cardiac surgical interventions by stating that "any surgeon who wishes to preserve the respect of his colleagues would never attempt to operate on the heart" [5]. Over the last 6 decades, the specialty of pediatric cardiac surgery has evolved from a heroic effort with occasional success into a consolidated, sophisticated specialty with excellent outcome [6].

The history of pediatric heart surgery initially coincided with that of cardiac surgery itself. By far the majority of early extra and intracardiac procedures was in fact performed to address various forms of congenital heart diseases rather than acquired heart disease. The adventure of intra-cardiac repair of congenital heart defect (CHD), in turn paved the way for technical advancements that pushed forward the field of adult cardiac surgery [7].

In the continental Africa, the numbers of people with heart complaints were noticed by Dr. Albert Schweitzer in 1921 after his first sojourn as physician and surgeon in French Equatorial Africa from 1913 to 1917. Miller et al. [8] was quoted as having said that the high prevalence of mitral stenosis was astonishing and that the sufferers needed to be helped with penicillin prophylaxis and cardiac surgery when indicated and that the same scenario existed for those with correctable congenital cardiovascular diseases [9].

Apparently, the transition paradigm from infections to noncommunicable diseases could have started about the same time around the world, however, in sub Saharan Africa the paradigm led to neglect of pre-transition of cardiovascular burden among the young. South Africa and North African countries like Egypt, Morocco and Algeria paralleled the western countries in the development of surgical management of cardiovascular diseases. In the West and East as well as Central Africa, the scope of cardiac operations falls short of expectations of the $21^{\text {st }}$ century world $[10,11]$.

Conventional open access heart surgery is not available in most African countries, but in the developed world including Egypt and South Africa, minimal invasive heart surgery is fast replacing the traditional or conventional types. The goal of minimal access surgery is to reduce pain, scarring and inflammatory response while maintaining the proven surgical efficacy of the conventional open approach $[12,13]$. Coronary artery revascularization has been the main beneficiary of this new technique, although significant strides have also been made in cardiac valvular surgery, arrhythmia surgery and congenital cardiac surgery [14]. In most of the patients presenting for intra-cardiac repairs in our centre, be it adult or pediatric, the conditions worsen to the extent that $80-90 \%$ are in NYHA, class III or IV, which relatively contraindicates minimal access procedures.

Interventional cardiology is gradually taking root in the center in particular and in Nigeria in general [15]. Coronary angiography and transvenous pacemaker implantation are established expertise. Their records are not captured since they were done by interventional cardiologists. The center lacks the expertise and technology for devise closure of ASD or VSD as well as implantation of cardiac valves.

\section{Materials and Methods}

This is a retrospective study. The hospital data base was used and consequently all patients that had cardiac operations from March 2013 to February, 2016 had their case files retrieved from the hospital record department. The inclusion criteria were those that had surface or open heart operations during the period. Those that had revisit to the theater for opening and reoperation for complication related issues were excluded. Also those that had thoracic operations or cardiac pathology not operated on who either died or were referred out were excluded from the study. There were 215 cardiac operations during the period but 6 were excluded because they were revisits to theater for reoperation on account of complications.

The data retrieved and analyzed were patients' demographics (age range, sex), the types and number of surface and open heart surgeries as well as their indications. Also included in the analysis were the types of congenital heart defects and acquired heart diseases managed surgically as well as the intra-operative and immediate postoperative complications. These were analyzed using SPSS version 4.0.

\section{Results}

We observed that the category of cardiac pathologies managed surgically consisted of both congenital heart defects and acquired heart diseases (Table 1 and Figure 1). Pericardial procedures such as pericardiostomy and pericardiectomy were the highest $35(16.8 \%)$ followed by isolated ventricular septal defect 30 (14.4\%). The least was repair of Sinus of Vasalva aneurysm 3 (1.4\%), followed by combined mitral valve replacement and modified de Vega annuloplasty of the tricuspid valves, 4 (1-9\%).

For the age distributions, the age range 0-10, 70 (33.5\%) was the highest followed by the age range 41-50, 58 (27.8\%). The least in the age range was $71-80,1(0.6 \%)$, closely followed by $61-70,5$ (2.4\%) (Table 2 and Figure 2).

\begin{tabular}{|l|l|c|c|}
\hline S/N & Indications & Numbers & $\begin{array}{c}\text { Percentages } \\
(\mathbf{\%})\end{array}$ \\
\hline 1 & Patent ductus arteriosus (PDA) & 21 & 10 \\
\hline 2 & Tetraology of fallot (TOF) & 13 & 6.2 \\
\hline 3 & Pericardial effusion and constrictive pericarditis & 35 & 16.8 \\
\hline 4 & Atrial septal defect (ASD) & 20 & 9.6 \\
\hline 5 & Ventricular septal defect (VSD) & 30 & 14.4 \\
\hline 6 & Aortic valve disease (AVD) & 10 & 4.8 \\
\hline 7 & Mitral valve disease (MVD) & 32 & 15.3 \\
\hline 8 & Aortic and mitral valves (DV) & 8 & 3.8 \\
\hline 9 & Tricuspid valve disease (TVD) & 6 & 2.9 \\
\hline 10 & Mitral and tricuspid valve diseases & 4 & 1.9 \\
\hline 11 & Atrial myxoma & 9 & 4.3 \\
\hline 12 & Ruptured sinus of vasalva aneurysm (RSVA) & 3 & 1.4 \\
\hline 13 & Truncus arteriosus, type 1 & 2 & 1.0 \\
\hline 14 & Pulmonary atresia, VSD with MAPCAS & 1 & 0.5 \\
\hline 14 & Atrioventricular cana defect (AVCD) & 1 & 0.5 \\
\hline Total & & 209 & 100 \\
\hline & & & \\
\hline
\end{tabular}

Table 1: The indications for cardiac operations in 3 years.

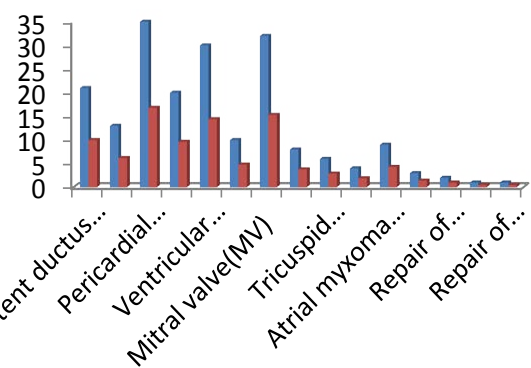

Numbers

Percentages(\%)

Figure 1: The indications for cardiac operations in 3 years. 


\begin{tabular}{|c|c|c|c|}
\hline S/N & Age range & Number & Percentage \\
\hline 1 & $0-10$ & 70 & 33.5 \\
\hline 2 & $11-20$ & 30 & 14.4 \\
\hline 3 & $21-30$ & 15 & 7.2 \\
\hline 4 & $31-40$ & 20 & 9.6 \\
\hline 5 & $41-50$ & 58 & 27.8 \\
\hline 6 & $51-60$ & 10 & 4.9 \\
\hline 7 & $61-70$ & 5 & 2.4 \\
\hline 8 & $71-80$ & 1 & 0.6 \\
\hline Total & & 209 & 100 \\
\hline
\end{tabular}

Table 2: Age distributions.

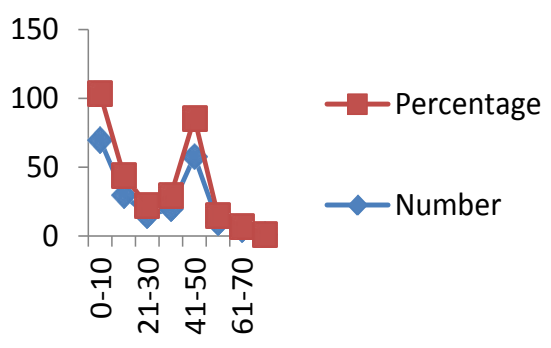

Figure 2: Age distributions.

\begin{tabular}{|c|c|c|c|}
\hline S/N & Age range & Male & Female \\
\hline 1 & $0-10$ & 43 & 27 \\
\hline 2 & $11-20$ & 19 & 11 \\
\hline 3 & $21-30$ & 13 & 2 \\
\hline 4 & $31-40$ & 14 & 6 \\
\hline 5 & $41-50$ & 32 & 26 \\
\hline 6 & $51-60$ & 6 & 4 \\
\hline 7 & $61-70$ & 2 & 3 \\
\hline 8 & $71-80$ & 1 & 0 \\
\hline Total & & 128 & 81 \\
\hline
\end{tabular}

Table 3 shows gender distribution; males 128 (61.2\%) were higher than females, 81 (38.8\%). This male domination was uniform in all the age range groups except the 61-70 age range.

Table 4 shows indications for procedures in CHDS. In the congenital heart defects treated surgically, isolated ventricular septal defect, 35 (44.8\%) was the highest, followed by isolated atial septal, 20 (29.9\%). The least was pulmonary atresia and atrioventricular defect, 1 (1.5\%) respectively followed by truncus arteriosus, 2 (3.0\%). Among the VSD with intracardiac repair, there were perimembraneous (subaortic, subpulmonic and inflow) and muscular types. The incidence of residual flow after repair was $0.06 \%$, which was insiginificant. ASD repair consisted of mainly secundum, primum, and superior sinus venosus types. There was no inferior sinus venosus type repair observed in our study.

The indications for intra-cardiac operations in adults were mainly valvular heart diseases. Top in the list of these indications is isolated mitral valvular heart disease which have 32 , representing $43.2 \%$. This is closely followed by isolated aortic valvular heart diseases, which have 10 and represent $13.5 \%$. The least of the indications are mitral and tricuspid valvular heart diseases which have 4 (5.4\%) and are followed by aortic and mitral valvular heart diseases, which have 8 (10.8\%).

We observed both intra-operative and postoperative complications in our study as highlighted below (Tables 5 and 6). Arrhythmias

\begin{tabular}{|c|c|c|c|}
\hline $\mathbf{S} / \mathbf{N}$ & Indications & Number & Percentage (\%) \\
\hline 1 & ASD & 20 & 29.9 \\
\hline 2 & VSD & 30 & 44.8 \\
\hline 3 & TOF & 13 & 19.4 \\
\hline 4 & Truncus arteriosus & 2 & 3.0 \\
\hline 5 & Pulmonary atresia & 1 & 1.5 \\
\hline 6 & Atrioventricular canal defect & 1 & 1.5 \\
\hline Total & & 67 & 100 \\
\hline
\end{tabular}

Table 4: Indications for open heart surgery or intracardiac operations.

\begin{tabular}{|c|c|c|c|}
\hline S/N & Indications & Number & Percentage (\%) \\
\hline 1 & AV & 10 & 13.5 \\
\hline 2 & MV & 32 & 43.2 \\
\hline 3 & AV+MV (DV) & 8 & 10.8 \\
\hline 4 & MV+TV & 4 & 5.4 \\
\hline 5 & Atrial myxoma & 9 & 12.2 \\
\hline 6 & RSVA & 3 & 4.1 \\
\hline 7 & TV & 6 & 8.1 \\
\hline 8 & CABG & 2 & 2.7 \\
\hline Total & & 74 & 100 \\
\hline
\end{tabular}

Table 5: Indications for open heart surgery or intra-cardiac Operations in the adult age group.

\begin{tabular}{|c|c|c|c|}
\hline $\mathbf{S} / \mathbf{N}$ & Complications & Number & Percentage (\%) \\
\hline 1 & Surgical bleeding & 9 & 21.4 \\
\hline 2 & Nonsurgical bleeding & 7 & 16.7 \\
\hline 3 & Septic shock & 3 & 7.1 \\
\hline 4 & Low cardiac output syndrome & 5 & 11.9 \\
\hline 5 & Arrhythmias & 12 & 28.6 \\
\hline 6 & Acute corpulmonale & 6 & 14.3 \\
\hline Total & & 42 & 100 \\
\hline
\end{tabular}

Table 6: Common postoperative complications in the intensive care unit.

especially atrial arrhythmias were significant, constituting about $12(28.6 \%)$ of all the complications noted during the review period. Surgical bleeding, both surgical and non-surgical types also featured prominently. It represented $9(21.4 \%)$ and $7(16.7 \%)$ respectively. The least of the witnessed complications is low cardiac output syndrome which represented 3 (7.1\%).

\section{Discussion}

Recent advances in the diagnosis, medical management, surgical techniques and nursing care including the participation of surgical missions from Europe and America as well as India have increased the scope of definitive surgical management of patients with cardiac diseases at NCTCE.

University of Nigeria Teaching Hospital, UNTH, Enugu was established in 1974 by a decree number 23 , immediately after the Nigeria civil war under the management of the Governing Council of University of Nigeria, Nsukka [16]. It became independent body in July, 1976 with autonomous Management Board. The return of the US and European trained personnel from UCH Ibadan, notably, Prof Udekwu led to the establishment of cardiothoracic and cardiovascular units in the department of surgery of the faculty of medicine and surgery. Consequently, the ingenuity of these few professionals in being the first institution to perform open heart surgery in Nigeria, just few years after the civil war and 11 years after the first open heart surgery in the world, impressed on the Federal government of Nigeria to designate the priocardiothoracic, cardiovascular and cardiology units as the National Cardiothoracic Center of Excellence in 1984 [1]. 
As the units were initially built on excellence, between 1975 and 1979, 46 children with cardiovascular diseases had been treated surgically. Such patients of age range, between 0-6 months and 10-16 years had extra-cardiac surgeries [2]. The surface heart procedures done were division and suture closure of PDA, BTS, and Water-Cooley shunt, repair of ectopic cordis, pericardiostomy and pericardiectomy as well as cardiorraphy for cardiac injuries including intra-cardiac procedures without $\mathrm{CPB}$. Such procedures were repair of ASD using inflow occlusion technique, mitral valve commissurotomy and aortic valve replacement. In the continental Africa and internationally, the cardiothoracic, cardiovascular and cardiology units of UNTH, were at the same level in the scope of cardiac surgeries performed then.

However, there was a great decline in the scope of heart surgery at the center subsequently, for by the year 2000 , only 102 cases of open heart surgery had been performed (1974-2000), averaging about 3.9 cases per year. Between 2000 and 2004, a total of 130 cases of heart surgeries were performed [4], averaging about 26 cases per year. Eze et al. 2007 explained the inconsistency to be due to political instability in our country with attendant brain syndrome, high cost of surgery, inadequate medical and surgical training for some staff who decided to remain in the country in the wave of brain drain, non-availability of high technology within the country and high cost of importing the equipment, inter-professional conflicts among health workers and poor infrastructural facilities in the health institutions [4]

In the emerging trend, training and retraining of staff and provision of equipment created unprecented impact in the center. Thus between $3^{\text {rd }}$ March, 2013 and February, 2016, the NCTCE recorded a total of 209 cases of heart surgeries, with a mean of 69.7 cases per year, covering a wide spectrum of cardiac pathologies (Table 1 and Figure 1). Thus the center became the first institution in Nigeria to manage truncus arteriosus, type 1 successfully as well as carried out unifocalisation and central shunt as the preliminary stage in the management of pulmonary atresia, with VSD and major aortopulmonary collaterals (MAPCAS).

In 1983, Cote D'Ivore, a West African country, recorded 300 cases of heart surgery comprising 149 valve replacements, 100 congenital cardiac surgeries, 40 surgeries for endomyocardial fibrosis and 7 others [10]. By 1987, the volume had gone up to 851 cardiac surgeries. The cardiac team was led by Yagni Angate. The trend had fallen drastically due to economic difficulty and civil strife [17]. At the thoracic and cardiovascular surgery Department of Dakaar Fann's university teaching hospital in Senegal, 4 patients with cardiac diseases were treated surgically in 1995, five years after establishing the centre but between 1996 and 2010, 15 years down the line, 13 million cases of cardiac surgeries were recorded, covering a wide range of adult and paediatric cardiac diseases [18]. This center is very active.

In Ghana, Nigeria's West African neighbour, the first open heart surgery was done in 1964 using the technique of surface cooling by a team led by professor C. O Easmon, just few years after Gibbon did his famous ASD using CPB [19]. Later, political instability and economic downturn affected this developmental work. With the return of a German trained Ghanaian, Professor Frimpong Boateng, the cardiac surgery became reawakened in 1989 and the establishment a cardiac center in Ghana in 1992, created a watershed in the practice of cardiac surgery in the West African subcontinent [19]. Between 1992 and 1995, Edwin et al. 2009 emphasized that about 100-120 cases of cardiac operations were carried out in the center averaging of about $25-30$ cases per year and by the year 2008 , about 464 operations had been done, with intra-cardiac operations constituting about 25\% [20]. Indeed, Ghana center has been recognized as excellent center by the
West African College of Surgeons for the training of cardiothoracic surgeons in the sub-region.

Kenya and Sudan were the latest countries to kick start cardiac surgery in their sub-region but suboptimal natural resources, civil wars and terrorist activities created major obstacles that limited the potential for growth and expansion [21].

Internationally, our center with 209 cases in 3 years is very low in the volume and spectra of cardiac operations in this $21^{\text {st }}$ century for in Brazil, a heart center, The Heart Institute Inc, performed a total of 71,000 cardiac operations between 1984 and 2007 with a mean of 2,977 cardiac procedures per year or 8 cardiac procedures per day [22]. These procedures included both simple and complex open and close cardiac procedures for both adult and paediatric cardiac diseases. Also, a German Heart center in Munich did 26,378 paediatric cardiac operations between 1999 and 2004 [23] with a mean of about 22,000 cases per year and these procedures included repair of congenital heart defects in any aige group including premature, neonates and children.

America and Europe, have the highest concentration of cardiac surgeons per million of their population as described by Turino et al. [24] who showed that the following distributions of heart surgeons per million of population: North America and Western Europe-278, Eastern Europe-30, South America-2.6, Asia-0.99 and Africa-0.26. Even within Africa, the highest concentrations will be found in North Africa and South Africa, leaving east, west and central Africa with meager number.

In our 209 cases done in 3 years, the age range of patients involved was between 0-10 and 71-80 years, (Table 2 and Figure 2) with those in the bracket of $0-10$ years contributing about $35.5 \%$. These were mainly paediatric, which of course were those with congenital heart diseases. This was followed by the age range of 41-50 years, who were early middle age and their pathologies consisted of acquired heart diseases, for example, pericardial diseases, rheumatic valvular heart diseases and heart injuries. The least age range involved was the 71-80 years. Here $\mathrm{CAD}$ and pericardial diseases predominated. The findings in our study is in contrast with work done by Fahid et al. where he demonstrated that the incidence of cardiac surgery tends to show increasing number among the elderly with CABG being the common procedure [25].

In our study, males constituted $128(61.2 \%)$, while females were $81(38.8 \%)$ representing a ratio of 1.6:1 (Table 3 and Figure 3). The findings are in agreement with the works of Bhardwaji et al. in India, where 150 patients between 1-5 years underwent cardiac operation in a year and males were $53.3 \%$ and females were $44.7 \%$ [26]. Also in Pakistan, 123 patients between the ages of 1-16 years had cardiac surgery for the period of 2008-2010. In their study, the males were 71 $(57.7 \%)$ and females were $52(42.3 \%)$ with a ratio of $1.3: 1$ [27]. That is to say that cardiac diseases are commoner in males than females.

Of the 209 cases of cardiac surgeries, the indications for open heart surgery or intra-cardiac operations were 125 (59.6\%), while those for surface heart surgery or extra-cardiac operations were $84(40.4 \%)$, with a ratio of 1.5:1. In the open heart surgery indications, acquired adult heart diseases were $79(63.1 \%)$ while congenital heart diseases represented 46 (36.9\%); (Tables 4 and 5; Figures 4 and 5). In NCTCE, Korlebu, Accra Ghana, in 464 cases done between, 1996 and 2008, 25\% were intra-cardiac operations while $75 \%$ were extra cardiac operations [20]. In India, the work of Zahid et al. comparing CHD and acquired heart disease, among 150 children below six years that had cardiac surgery, it showed that congenital heart defect constituted $89.3 \%$ while acquired heart disease was $10.7 \%$ [27]. In this same study, acyanotic 


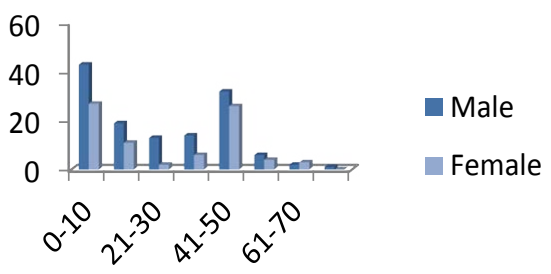

Figure 3: Sex distributions

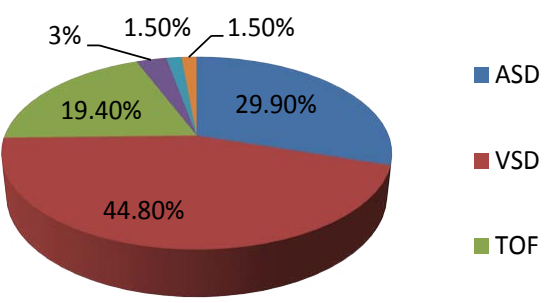

Figure 4: The paediatric age group.

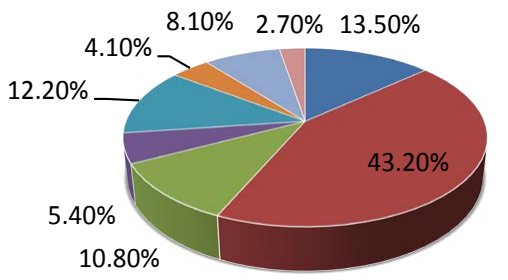

AV
MV
AV+MV(DV)
MV+TV
Atrial myxoma
RSVA

Figure 5: Indications for open heart surgery or intra-cardiac Operations in the adult age group.

heart defect was $74.6 \%$ with VSD (29.9\%) and ASD (25.4\%), while cyanotic heart defect was $23.9 \%$ with TOF being $11.2 \%$. Our own study agrees with their findings that acyanotic heart defects are commoner than cyanotic defect in the paediatric age group, Figure 4 . Nwiloh et al. 2014 studied 24 patients that had open heart surgery in Nigeria other than NCTCE in about 2 years (2004-2006). In the 24 patients, males were 13 while females were 11 . Mechanical valve replacement due to rheumatic valve diseases were 12, septal defects repair (ASD and VSD) were 11 while tumour excision, atrial myxoma was 1 . The low ebb of cardiac surgery in Nigeria is improving when this report is compared with our study [28].

In the postoperative period, many complications were noted and these occurred in the $1^{\text {st }} 24$ and 48 hours while the patient was still in the intensive care unit (Table 6 and Figure 6). Such complications were bleeding which were either surgical or nonsurgical. The management of surgical bleeding when identified included returning the patient to the theatre, opening the operation site and securing the bleeding vessel(s). The nonsurgical causes which could be inadequate reversal of heparin, deficiency of coagulation factors, thrombocytopaenia or thrombocytopathy and hyper fibroginaemia, were managed appropriately with specific agents when identified. It is noteworthy that in the course of such managements, morbidity and mortality occurred. Other notable postoperative conditions such as low cardiac output syndrome and septic shock also constituted challenges in the course of their management and indeed added to the degree of morbidity and mortality encountered generally. The acute corpulmonale as a complication encountered in our study occurred in the intra-operative period and caused prolongation in the bypass time and in few cases led to DOT (death on table).

Indeed the mortality rate has fallen as the practice of cardiac surgery evolved in our center. In the previous publications by Anyanwu et al. and Eze et al. the actual survival rate was about $45 \%$ and $63 \%$ respectively $[2,4]$. In this study, the survival rate has increased to $85 \%$, as 30 day mortality rate was $15 \%(31 / 209)$. Nwiloh et al. recorded a 30 day mortality rate of $8.3 \%(2 / 24)$ [28] in the 24 patients studied. This success can be attributed to better understanding of intricacies specific to cardiopulmonary bypass for those that had intra-cardiac operations as well as proper monitoring and availability of point of care tests. Also significant in this regard is the availability of high tech-equipment for making proper diagnoses.

With the return of Dr. Eze, JC from Texas Heart Institute, USA and subsequent headship of the center in 2008, training and retraining of staff became a very renovational change in the center coupled with provision of high tech-equipment through Tertiary Educational Trust Fund (TETF), all at the instance of Dr. Eze, JC's committee and the then Vice Chancellor of UNN, Prof Bartho Okolo (Figures 7-11). The trained staff upon return in 2013 made a tremendous turn around in the quality and quantity of patients with cardiac diseases requiring surgery, both intra-cardiac and extra-cardiac. Some staff that left the country due to brain syndrome became very much interested in the center and offered help through medical missions that occurred about thrice in a year for the three years.

\section{Conclusion}

Cardiac operations in our center within the three year period could judge to have increased relative to previous years but in the continental

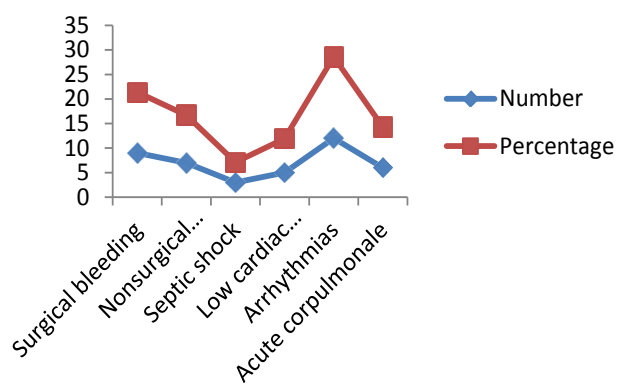

Figure 6: Common postoperative complications in the intensive care unit.

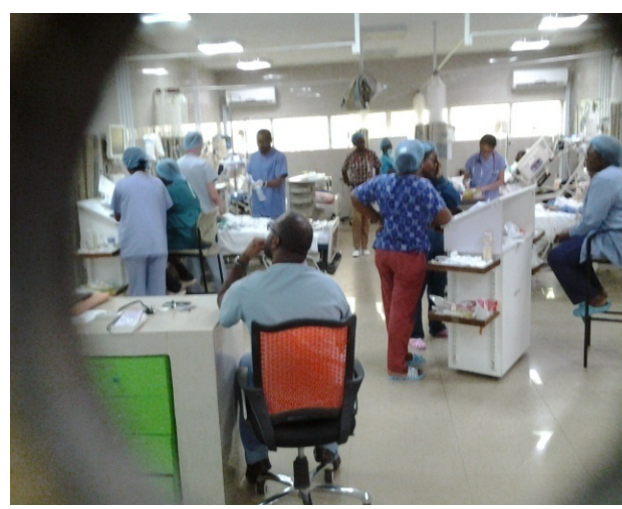

Figure 7: Cardiac team and patients in the cardiac ICU during one of the medical missions during one of the medical missions. 
Citation: Nwafor IA, Eze JC, Anyanwu CH, Ezemba N, Onyia UOC, et al. (2017) The Scope of Cardiac Surgery at a National Cardiothoracic Center of Excellence (NCTCE) in Nigeria: A 3-Year Review. J Vasc Med Surg 5: 308. doi: 10.4172/2329-6925.1000308

Page 6 of 7

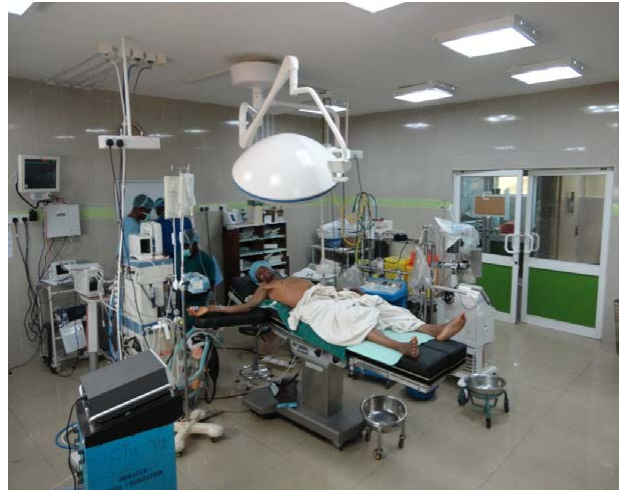

Figure 8: Cardiac theatre with patient awaiting pericardiectomy.

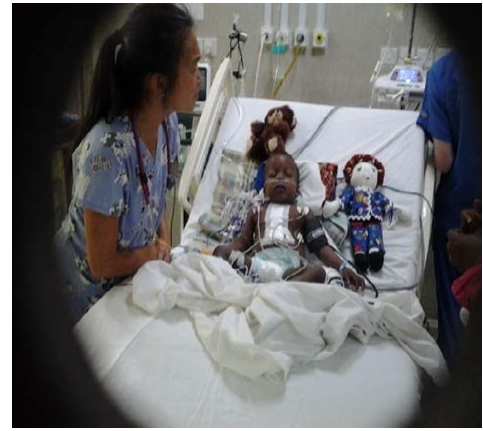

Figure 9: Postoperative intra-cardiac paediatric patient in cardiac ICU.

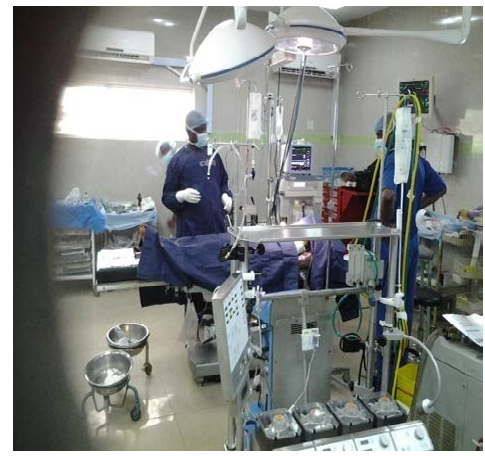

Figure 10: One of the two cardiac theatres at NCTCE.

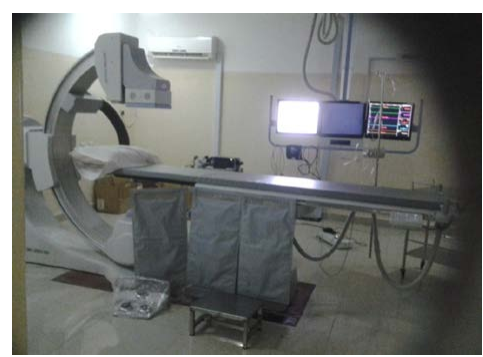

Figure 11: Cardiac catheterization suite

Africa in particular and the world in general, this is far below the expectation of a $21^{\text {st }}$ century heart center. However, cardiac surgery requires relatively sophisticated diagnostic and surgical technique and high level infrastructure operated by personnel with advanced training and expertise. This luxury is largely scarce in our country. It is hoped that continued cardiac missions with Nigerians in Diaspora and continuous training of the local staff coupled with ejection of educational trust fund will no doubt improve the rating of our center in the foreseeable future. The western world is fast changing from traditional open access heart surgery to minimal invasive access heart surgery, including robotic heart surgery. The technology and expertise are currently not available in our center. It is hoped that further research work in future will focus on comparing the open and minimal access technique for both extra-and intra-cardiac surgery in our center. The center is also looking forward that someday(s) in the future, its own local experts will provide foreign cardiac missions to other poor countries, not only in Africa but in the World.

\section{Conflict of Interest}

There is no conflict interest whatsoever.

\section{Acknowledgement}

I am highly indebted to the patients, the chairman, NCTCE, Prof Basden Onwubere and the secretarial staff, for their role in the production of this article.

\section{References}

1. Anyanwu CH, Ihenacho HNC, Okoroma EO, Nwafo DC, Umeh BU, et al. (1982) Initial experience with open-heart surgery in Nigeria Cariologie Tropicale. Tropical Cardiology.

2. Anyanwu CH, Okwara EO, Iheanacho HNG, Umeh BU (1981) Experience with surgical management of Congenital Heart Disease in Children. Nigerian Journal of Pediatrics 8: 94-97.

3. Adebonojo SA (2008) Open Heart Surgery in Nigeria. In Development of Open Heart Surgery in West Africa; A historical Perspective. Acecool Medical Publishers Nigeria, pp: 25-26.

4. Eze JC, Ezemba N (2007) Open Heart Surgery in Nigeria; Indications and Challenges. Tex Heart Inst J 34: 8-10.

5. Westaby S (2014) The foundation of cardiac surgery. In: Landmark in Cardiac Surgery. Oxford UK. Isis Medical Media Ltd.

6. Walhausen JA (1997) The early history of Congenital Heart Surgery: Closed heart operations. Ann Thorac Surg.

7. Carlon CA, Mondini PG, de Manchi K (1951) Surgical treatment of some cardiovascular diseases. J Int Coll Surg 16: 1-11.

8. Miller DC, Spencer SS, White PD (1962) Survey of Cardiovascular Diseases Among Africans in the vicinity of Albert Schweitzer Hospital in 1960. Am J Cardiol.

9. Murray CJ, Lopez AD (1997) Alternative projections in mortality and disability by case, 1970-2000. Global Burden of Diseases Study. Lancet 349: 1498-1504

10. Metras D, Ouezzin-Coulibaly A, Ouattara K, Chauvet J, Longechaud A, et al. (1985) Open Heart Surgery in Tropics-Results and Peculiar Problems of the 1st 300 cases of Extracorporeal Circulation in Abidjan. La Pressa Medicale 12: 621-624.

11. Edwin F, Sereboe LA, Tettey MM, Aniteye EA, Kotei DA, et al. (2010) Experience from a single Center concerning the surgical spectrum and outcome of Adolescents and Adults with congenitally malformed hearts in West Africa. Cardiol Young 20: 159-164.

12. Davy CHC, Janet M, Avtar L, Anno D, Thierry DF, et al. (2011) Minimally Versus Conventional Open Mitral Valve Surgery. A meta- Analysis and Systemic Review. Innovations 6: 84-102.

13. Eze JC, Nwafor IA, Ezemba N (2013) Open heart Surgery: Comparative prosthetic valve utilization at two centers. Chirurgia 26: 69-72.

14. Tonger JD, Doty JR (1998) The expanded role of minimal invasive coronary artery grafting. Eur J Cardiothoracic Surg 14: 3-6.

15. Chinawa JM (2014) The practice of Paediatric Cardiology in Nigeria, A Review. Nigeria Journal of Pediatrics-African Journal Online (AJOL) 41: 12-15. 
Citation: Nwafor IA, Eze JC, Anyanwu CH, Ezemba N, Onyia UOC, et al. (2017) The Scope of Cardiac Surgery at a National Cardiothoracic Center of Excellence (NCTCE) in Nigeria: A 3-Year Review. J Vasc Med Surg 5: 308. doi: 10.4172/2329-6925.1000308

16. Nnamdi Azikiwe (2014) The University of Nigeria Speech by. Blackpast.org. Blackpast.org.

17. http://news.smh.au/breaking-news-world/heart-surgeons-find-their-way-insnegal-2110426-htm

18. Frimpong Boateng K (2000) Accra: Edited by Woeli publishing Services. The beginning of cardiothoracic surgery in Ghana. Deep down in my heart.

19. Edwin F, Tettey M, Aniteye E, Tematey M, Serebroe L, et al. (2011) Development of cardiac surgery in West Africa. Pan Afr Med J.

20. Edwin $F$ (2011) The future of heart surgery in Ghana. Paper presented to the Walter Sisulu Pediatric Cardiac Foundation; Tintswalo at Waterfall Lodge.

21. Ribeiro GS, Tartol SY, Oliveira DSW, Guedes ACS, Reis MG, et al. (2012) Surgery for Valvular Heart Disease. A pop-based study in a Brazilian urban center. PloS ONE.

22. Funkat A, Beckmann A, Lewandoski J, Frie M, Schiller W, et al. (2014) Cardiac surgery in Germany during 2013: a report on behalf of the German Society for Thoracic and Cardiovascular Surgery. Thorac Cardiovasc Surg.
23. Turina MI (2002) European Association for cardiothoracic: carrying thr torch. Eur J Cardiothoracic Surg 22: 857-863.

24. Fahid JS, Shahid AS (2007) A decade of cardiothoracic surgery at a tertiary care hospital in Karachi. Pakistan, JPMA.

25. Bhardwaji R, Rai Sk, Yadav AK, Laklolia S, Agrawal D, et al. (2015) Epidemiology of Congenital Heart Disease in India. Congenital Heart Disease 10: 437-446.

26. Edwin F, Frimpong-Boateng K (2011) Open-heart Surgery and coronary artery bypass grafting in West Africa. Pan Afr Med J.

27. Zahid SB, Ahmed SA, Achakpai H (2013) Spectrum of Congenital Heart Diseases in Children admitted for cardiac surgery at Rehman Medical Institute Peshawar, Pakistan. Park J Med Sci 29: 173-176.

28. Nwillo JO, Oludara MA, Adesola PA (2014) Heart Surgery Practice in subsaharan Africa. Single Nigerian Institutional Midterm Results and challenges. WJCS 4: 35-41. 